Journal of Teacher Education for Sustainability, vol. 18, no. 2, pp. 89-104, 2016

\title{
Using Excel in Teacher Education for Sustainability
}

\author{
Serhat Aydin \\ Karamanoğlu MehtmetBey University, Turkey
}

\begin{abstract}
In this study, the feasibility of using Excel software in teaching whole Basic Statistics Course and its influence on the attitudes of pre-service science teachers towards statistics were investigated. One hundred and two pre-service science teachers in their second year participated in the study. The data were collected from the prospective teachers before and after the compulsory Basic Statistics Course. This is a course offered in the third term aiming at introducing the most basic concepts and operations in descriptive and inferential statistics. In the context of this course, it could be argued that in most universities basically four concept groups are addressed: 1) Data and distributions, 2) How values cluster and/or disperse, 3) How variables move, classify or cluster jointly and 4) How the means between different groups differentiate.

The statistics course with the content mentioned above is usually handled theoretically and nearly no statistical software is used considering the needs and expectations of pre-service science teachers. In case a software is used, it is generally SPSS in Turkey. SPSS is nearly the standard in the field here and dominates all other software such as SAS etc. On the other hand, Excel with much of its capabilities, accessibility and ease of use, is not considered by most of the academics as sufficient statistical software.

In this paper the capabilities, accessibility and practicality of Excel program in teaching most basic statistics course topics to pre-service science teachers were demonstrated and its superiority to other softwares and traditional instruction were discussed. In addition, the positive effect of such an instruction on the attitudes of pre-service teachers towards statistics was shown.
\end{abstract}

Keywords: Teacher Education, ICT, Excel, Statistics, Attitudes

\section{Introduction}

"That's one primary reason that an application such as EXCEL, or an application specifically and solely designed for statistical analysis, is so helpful. It takes the drudgery of the arithmetic off your hands and frees you to think about what the numbers actually mean.

Statistics is conceptual. It's not just arithmetic. And it shouldn't be taught as though it is." 
Microsoft EXCEL is a versatile software which offers a wide range of applications ranging from data management to statistical analysis (Gomes, Passeri and de Albergaria Barbosa, 2006). Ms EXCEL provides tools for simple statistical analysis, such as ttests, F-test, correlation and regression (Slezák, Bokes, Námer, and Waczulíková, 2014). Duller (2008) believes that Excel can be used to teach statistics in many ways. By using Excel in teaching statistics, one can use simulations to teach distributions (Carlberg, 2014; Doane, 2004) or to demonstrate the statistical power of an experiment and to explore experimental variability (Horgan, 1999). Bartz (2007) showed how to use Excel to calculate and illustrate probabilities. In some studies Excel was used to illustrate combinatorial ideas (Kühleitner, 2007; Borovcnik, 2007).

More importantly than the variety in the ways Excel can be used in teaching statistics, statistical softwares such as EXCEL have the capacity to promote conceptual learning in statistics (Carlberg, 2014). Price and Zhang (2007) used Excel to enhance understanding important ideas in statistics and Nash and Quon (1996) implemented Excel to develop statistical thinking. Newfeld (2016) used Excel assignments to quickly cement in the students' minds both the applicability of statistics course materials in the real world as well as their own ability to master it. In a series of studies, Hunt $(2003,2005$, and 2007) used Excel to prepare individualized tasks for students. Therefore, it can be seen that Excel can be used in teaching several statistics topics in a variety of ways and for developing various skills and attaining various practical benefits.

Despite all these benefits, Duller (2008) states that teaching statistics is a big challenge and teaching it with Excel is even a bigger one. However, he adds that one has to accept to use it because the other special softwares are either expensive or requires technical expertise such as using command line interfaces (Duller, 2008). In other words, he finds Excel the easiest and most accessible - one might prefer to call it sustainable software in teaching statistics. Considering that one in seven people on the planet (Microsoft, 2016) uses Excel and in most cases all university students possess that software, it would be wise to attempt to use it in teaching statistics in teacher education.

Research on Education for Sustainable Development (ESD) reveals that instructors mostly do not buy expensive or learn techno-rich software and technologies and thus can not use ICT and transfer it to real life situations sufficiently for ESD (Makrakis, 2011). One of the most important points in ESD for teachers is the diffusion of ICT to teachers which requires wider use of available technology. One important keyword is "access" and another is "wider use" as can be seen from the following quote. Makrakis and Makrakis (2012) summarize the major challenges that need to be addressed to merge ICT successfully to ESD:

- Education sectors are lagging behind to capitalise on ICTs potential in promoting ESD.

- ICTs can empower and help to facilitate greater access to ESD learning by disadvantaged people, marginalised groups and communities. However, the 'digital divide' still remains a major challenge.

- ESD planning with new pedagogy is an essential part of building a whole school approach to ICT-enabled ESD.

- Dissemination and communication of information on innovative ICT-enabled ESD examples and practices may provide opportunities for embedding ESD in the curriculum supported by ICTs.

- A vision that facilitates an education model responsive to the development of ICT-enabled ESD is often missing among education planners and policy makers. 
Using Excel in teacher education for teaching most (if not all) statistics topics can be thought of as one possible solution for some of the challenges listed above. Although, there are some useful applications and benefits of using Excel in teaching statistics, there're some points worth considering in which further empirical research is still needed. The literature on using Excel in teaching statistics is still:

- Incomplete about the topics in which Excel can be used (diffusion),

- Sparse about how Excel influences student learning and development,

- Inconclusive about how Excel influences student beliefs, emotions and attitudes,

- Scarce about using Excel in teacher education, specifically in science teacher education (wider use),

- Replete with inconsistent and contradictory findings regarding its merit relative to other commercial softwares,

- And finally underdeveloped in terms of using empirical evidence.

Despite all these gaps in the literature there's still not much work in reaction. Although the discussions above show that Excel can be used in teaching several statistics topics, developing various skills and attaining various practical benefits, the problem is there's still not much evidence whether it can be used to teach a whole undergraduate statistics course. There's also not a substantial evidence how this will effect attitudes towards statistics. Therefore, the purpose of this study is to demonstrate the feasibility of using Ms Excel in teaching whole Basic Statistics Course to pre-service elementary science teachers and then to show the effects of this treatment on pre-service teachers' atttitudes towards statistics. In this way, new empirical evidence will be provided about the problem. Therefore the research questions of this study are:

1. What is the feasibility of using Ms Excel software in teaching a whole course (Basic Statistics) to pre-service elementary science teachers?

2. What is the effect of this instruction on pre-service science teachers' attitudes towards statistics?

\section{Method}

The study uses both a case study approach and a pretest-posttest quasi-experimental design. In the case study the feasibility of using Ms Excel in teaching whole Basic Statistics Course to pre-service elementary science teachers were portrayed. After the portrayal, the effects of this treatment on pre-service teachers' atttitudes towards statistics were shown using a control group-treatment group quasi-experimental design. In the experimental phase

1. Attitudes towards statistics and mathematics are measured,

2. Theoretical instruction in control group and use of Excel in experiment group were performed,

3. Attitudes towards statistics and mathematics are measured.

\subsection{Study Group / Sample of the Study}

The sample of study is 102 pre-service teachers studying at a state university in the west of Turkey. The pre-service teachers were naturally as two different classes. The groups were assigned as control and test groups randomly. The sample of the study is shown in Table 1. 
Table 1

Study Sample

\begin{tabular}{lccc}
\hline & Control & Experiment & TOTAL \\
\hline Female & 35 & 36 & 71 \\
\hline Male & 17 & 14 & 31 \\
\hline TOTAL & 52 & 50 & 102 \\
\hline
\end{tabular}

\subsubsection{Instruments / Scales}

The attitudes of pre-service teachers towards statistics were measured using the Turkish version of the Survey of Attitudes toward Statistics-36 ${ }^{\odot}$ (SATS-36 ${ }^{\circ}$ ). It was developed by Schau (2003) and adapted into Turkish by Emmioğlu (2011). It is a recent instrument developed to assess attitudes toward statistics. Psychometric properties of the instrument are well documented and supported by confirmatory analysis techniques (Chiesi and Primi, 2010; Tempelaar, Schim and Gijselaers, 2007). The subscales were based on a theoretical background (Schau, 2003). It includes 36 items with a sevenpoint response scale ( $1=$ strongly disagree, $4=$ neither disagree nor agree, $7=$ strongly agree) in which higher scores correspond to positive attitudes in six subscales: difficulty, value, cognitive competence, affect, effort, and interest.

The instrument was applied to both groups twice. Once as a pretest before the instruction and as a posttest after the instruction.

\section{Results}

The findings of the study will be revealed in two parts. First the findings related to the feasibility of using Ms Excel in teacher education will be presented. Then its effects on pre-service teachers' attitudes will be discussed.

\subsection{The Feasibility of Using Ms Excel in Teaching (all) Most Topics of Basic Statistics Course}

The feasibility of using Ms Excel in teaching (all) most topics of Basic Statistics Course will be shown in three stages. Firstly, the method used to teach basic statistics course to pre-service science teachers will be explained. Secondly, the topics of basic statistics that were taught in this context were listed. Thirdly, the feasibility of using Ms Excel in teaching most topics of Basic Statistics Course and the points where Excel has superiority or inferiority to other software will be discussed.

\subsubsection{The Method Used in This Study to Teach Basic Statistics Course to} Pre-service Science Teachers in Treatment and Control Groups

Basic statistics course is a one term 2 credits must course offered every third semester of science teacher preparation program. In this course basically four concept groups are addressed in Turkey: 1) Data and distributions, 2) How values cluster and/or disperse, 3) How variables move, classify or cluster jointly (including correlation and regression tests) and 4) How the means between different groups differentiate (including parametric and non-parametric tests such as F-test, t-test, Chi-square or Kruskal Wallis-H test.) The statistics course with the content mentioned above is usually handled theoretically 
and nearly no statistical software is used. It's usually seen as unnecessary to show preservice science teachers how to use SPSS or other statistical software. Other software which require more technical skills SAS or Matlab etc. are not also widely used in statistics courses of pre-service teachers. On the other hand, Excel with much of its capabilities, accessibility and ease of use is not considered by most of the academics as a sufficient statistical software.

In this study, the study group was divided into two subgroups. One group was randomly chosen as control and the other group as the treatment group. In both groups the instruction was based on the textbook by Carlberg (2011) named Statistical Analysis: Microsoft巴 Excel 2010. The book has a conceptual instruction method and additional datasets for each chapter to practice the concepts taught in each chapter. In the control group the concepts of basic statistictics, statistical tests, formulas and their interpretations were taught theoretically. In the treatment group all concepts, tests, graphs, tables and interpretations were given using Excel applications in the class. All pre-service teachers brought their notebooks, Excel software installed, datasets ready for each topic. Once the concept was introduced by the instructor, the Excel applications were examined by the pre-service teachers on their notebooks with the guidance of the instructor. In this way all the topics were covered in the treatment and control groups.

In addition, the pre-service science teachers in the treatment group were assigned application tasks in which they should find the dataset assigned for them from the website of Turkish National Statistics Institute. Then they should calculate, draw, illustrate, test or interpret a concept that was taught on the last lesson in the class. For example, if standard deviation was addressed on the last lesson, the pre-service teachers should use their unique datasets that they should download from Turkish National Statistics Institute to elaborate further at home and then to present to their peers in the next session. All students were assigned different and unique datasets to download for each application. The Excel files for these tasks and pre-service teachers' presentations of their tasks were evaluated and scored. The course grades were obtained totally from these tasks in the treatment group which were initially designed to be 12 times but in practice could only be performed 6 times.

\subsubsection{The Topics that Were Taught Using Excel Applications}

The following table will show you how Excel was and could be used in teaching most topics of basic statistics course in the treatment group.

Table 2

Basic Statistical Concepts Taught Using Ms Excel

\begin{tabular}{|c|c|c|}
\hline TOPIC & Objectives & $\begin{array}{c}\text { Action } \\
\text { Pre-service teachers can ... }\end{array}$ \\
\hline 1 & 2 & 3 \\
\hline \multirow{4}{*}{$\begin{array}{l}\text { Data and } \\
\text { Distributions }\end{array}$} & Recording Data & easily enter and analyze data \\
\hline & Variables & distinguish between different variable types \\
\hline & Charts and Graphs & $\begin{array}{l}\text { summarize the data using charts, graphs } \\
\text { and tables }\end{array}$ \\
\hline & Data fit & $\begin{array}{l}\text { understand the fit between the data and } \\
\text { graphs }\end{array}$ \\
\hline
\end{tabular}

Sequel to Table 2 see on the next page. 
Sequel to Table 2.

\begin{tabular}{|c|c|c|}
\hline 1 & 2 & 3 \\
\hline & $\begin{array}{l}\text { Observe regression } \\
\text { concept }\end{array}$ & $\begin{array}{l}\text { understand basic concepts of correlation } \\
\text { and regression with trendlines on graphs }\end{array}$ \\
\hline & Frequency distributions & understand frequency distributions \\
\hline & Frequency distributions & understand normality, skewness and kurtosis \\
\hline & Excel formulas & use FREQUENCY() formula for grouping \\
\hline & Distribution simulation & $\begin{array}{l}\text { show how a frequency distribution assumes } \\
\text { a normal distribution shape as the number } \\
\text { of underlying records increases using } \\
\text { formulas such as RAND() }\end{array}$ \\
\hline \multirow[t]{7}{*}{$\begin{array}{l}\text { Measures of } \\
\text { Central Tendency }\end{array}$} & Calculate the mean & $\begin{array}{l}\text { calculate the mean using the AVERAGE() } \\
\text { function }\end{array}$ \\
\hline & Excel formulas & $\begin{array}{l}\text { use array formulas for measures of central } \\
\text { tendency }\end{array}$ \\
\hline & $\begin{array}{l}\text { Excel SOLVER } \\
\text { SOLV }\end{array}$ & use Excel SOLVER to minimize the spread \\
\hline & Calculate the median & $\begin{array}{l}\text { calculate the median using the MEDIAN() } \\
\text { function }\end{array}$ \\
\hline & Mean vs. Median & $\begin{array}{l}\text { observe that the mean and the median are } \\
\text { always different in asymmetric distributions }\end{array}$ \\
\hline & Calculate the mode & $\begin{array}{l}\text { calculate the mode using the } \operatorname{MODE}() \\
\text { function }\end{array}$ \\
\hline & Excel formulas & look inside Excel formulas for central tendency \\
\hline \multirow{5}{*}{$\begin{array}{l}\text { Measures of } \\
\text { Dispersion }\end{array}$} & Calculate range & can measure variability with the range \\
\hline & Comprehend range & $\begin{array}{l}\text { understand that when the distribution is } \\
\text { approximately symmetric, the range is a } \\
\text { useful descriptor }\end{array}$ \\
\hline & $\begin{array}{l}\text { Understand standard } \\
\text { deviation }\end{array}$ & $\begin{array}{l}\text { understand when standard deviation is a } \\
\text { useful measure }\end{array}$ \\
\hline & $\begin{array}{l}\text { Calculate standard } \\
\text { deviation }\end{array}$ & $\begin{array}{l}\text { can measure variability with the standard } \\
\text { deviation using Excel functions }\end{array}$ \\
\hline & Calculate variance & $\begin{array}{l}\text { can measure variability with the variation } \\
\text { using Excel functions }\end{array}$ \\
\hline \multirow{6}{*}{$\begin{array}{l}\text { How Variables } \\
\text { Move Jointly: } \\
\text { Correlation }\end{array}$} & Understand correlation & $\begin{array}{l}\text { distinguish positive, negative and no correla- } \\
\text { tions on graphs }\end{array}$ \\
\hline & Calculate correlation & $\begin{array}{l}\text { calculate correlation using Excel's CORREL() } \\
\text { function }\end{array}$ \\
\hline & Calculate correlation & $\begin{array}{l}\text { calculate correlation using Excel's Correla- } \\
\text { tion tool }\end{array}$ \\
\hline & Understand regression & $\begin{array}{l}\text { observe and understand regression on scatter- } \\
\text { plot graphs }\end{array}$ \\
\hline & Calculate regression & $\begin{array}{l}\text { calculate regression function using Excel's } \\
\text { TREND() function }\end{array}$ \\
\hline & $\begin{array}{l}\text { Calculate multiple } \\
\text { regression }\end{array}$ & $\begin{array}{l}\text { calculate multiple regression function using } \\
\text { Excel's TREND() function }\end{array}$ \\
\hline \multirow{2}{*}{$\begin{array}{l}\text { Testing Differences } \\
\text { Between Means: } \\
\text { The Basics }\end{array}$} & Standard error & understands the term standard error of the mean \\
\hline & $\begin{array}{l}\text { Compare two } \\
\text { distributions }\end{array}$ & compare two distributions by visualizing \\
\hline
\end{tabular}


Sequel to Table 2.

\begin{tabular}{lll}
\hline 1 & \multicolumn{1}{c}{2} & \multicolumn{1}{c}{3} \\
\hline & z-test & understand and use z-test \\
\cline { 2 - 3 } & t-test & understand and use t-test \\
\cline { 2 - 3 } & F-test & understand and use F-test \\
\cline { 2 - 3 } & Statistical power & visualize statistical power using spinners \\
\hline
\end{tabular}

Table 2 shows that Ms Excel can be used to instruct most of the Basic Statistics Course content conceptually. Some sample screenshots can be presented for illustrative purposes. Figure 1 shows sample screenshots from the topic of frequency distributions.

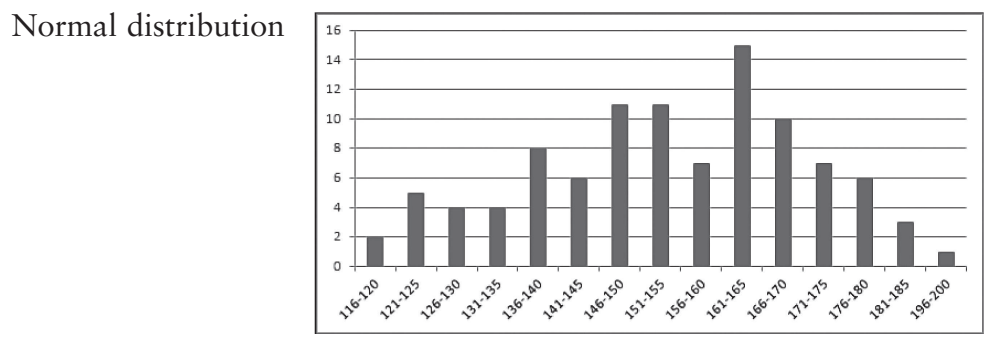

Negatively skewed distribution

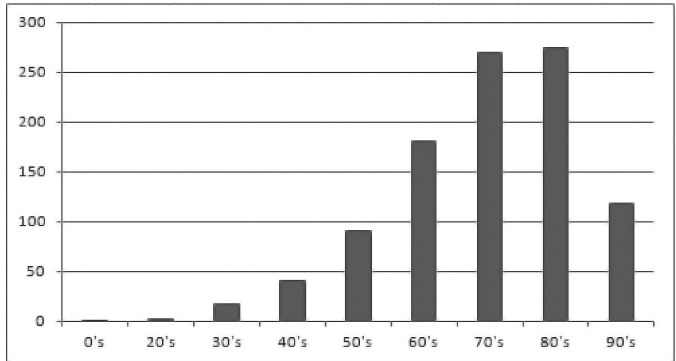

Positively skewed distribution

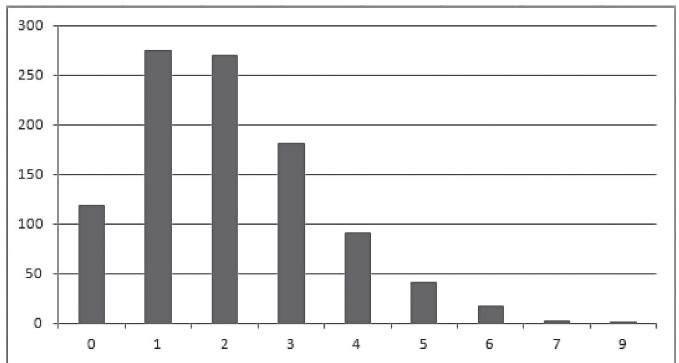

Figure 1. Screenshots of various distributions in Ms Excel

Figure 1 make it easier to comprehend intuitively what it means to be normal distribution or a skewed one. The figures help understand for example why negatively skewed distributions are encountered less in real life. Other screenshots can be shown in the topic of dispersion.

Figure 2 shows two distributions. The former distribution is an example where the range provides a meaningful statistics. The later one is an example where the range has little or no meaning. 
Range measure useful

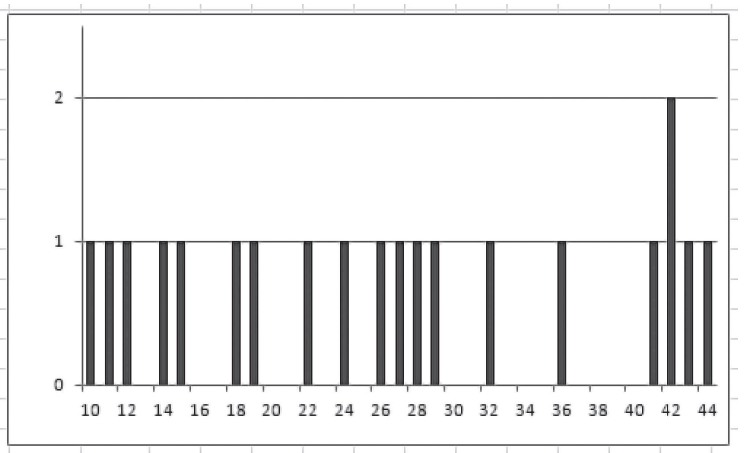

Range measure not useful

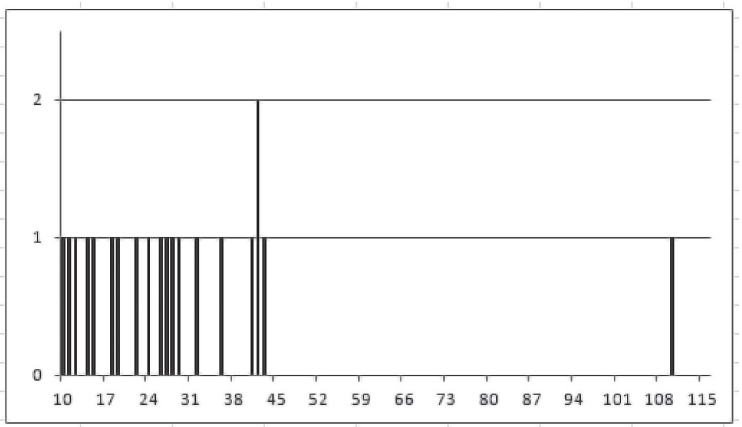

Figure 2. Screenshots of distributions in Ms Excel where Range is/isn't useful

\subsubsection{The Feasibility of Using Ms Excel in Teaching Whole Basic Statistics Course} and the Points where Excel has Superiority or Inferiority to Other Software

It was shown in this study that the topics shown in Table 2 could be taught and applied using Excel. These topics are almost all the topics that could actually be dealt in classes in science teacher training whether Excel was used or not. Excel's most important superiority is pre-service teachers' wide access to the software. All the pre-service teachers in the study had Excel 2010 installed on their computers. Another advantage and superiority is that pre-service teachers needed minimum guidance to basic skills to run the program, enter data, open and save files and create graphs. Excel has marvelleous graphs and a user-friendly interface that allowed pre-service teachers to understand the concepts such as mean, standard deviation, variance, correlation and regression visually and intuitively.

Besides the advantages there are also some disadvantages in using Excel to teach basic statistics to pre-service science teachers. First, Excel still has no built-in function for finding the mode of categorical variables (Carlberg, 2014). The precision in calculating the $p$-value is $10^{-3}$ where it is $10^{-4}$ in SPSS or SAS (Carlberg, 2014). However, this level of precision seems irrelevant by the author for providing conceptual statistic learning to pre-service science teachers. Another source of difficulty was the huge amount of time needed occasionally to solve even tiny technical problems such as difficulty in opening a file, finding the add-in like solver, detecting small errors that could prevent to run an important test. These difficulties showed that an assistant technician for each 3-4 students if not for all students would be very helpful to be able to cover all the topics and assessment planned beforehand. 


\subsection{The Effects of Using Ms Excel in Pre-service Teachers' Atttitudes towards Statistics}

In this part of the study, the effects of using Ms Excel in teacher education on preservice teachers' attitudes towards statistics will be presented. There are six steps in this procedure. First, the Turkish version of the Survey of Attitudes toward Statistics-36 ${ }^{\odot}$ $\left(\right.$ SATS-36 ${ }^{\circ}$ ) was applied to 102 pre-service science teachers before the instruction as a pre-test. A dataset was obtained from the answers to the survey. Using the dataset i) Exploratory Factor Analysis (EFA) was performed to reveal the factor (latent trait) structure, ii) Confirmatory Factor Analysis (EFA) was performed to confirm the factor (latent trait) structure, iii) Latent trait analyses (test and item levels) was performed using Item Response Theory (IRT) Rasch model to confirm the factor (latent trait) structure and check the scale, sub-scale and item level parameters for adequacy, iv) the means of pre-test scores in treatment and control groups were compared using t-test for independent samples. T+hen the Basic Statistictics Course began and the pre-service teachers who were split into two natural groups were assigned as treatment and control groups randomly. In the two groups the instruction was carried as described above in the method section. After the instructions in both groups, the Turkish version of the Survey of Attitudes toward Statistics-36 ${ }^{\circ}\left(\right.$ SATS-36 $\left.{ }^{\circ}\right)$ was applied to 102 pre-service science teachers once more as a post-test $\mathrm{v}$ ) the means of post-test scores in treatment and control groups were compared using t-test for independent samples, vi) The common effect of receiving a different instruction and being in a different group were investigated using F-test for mixed measurements. The findings from these steps are presented in the following sections in more detail.

\subsubsection{Exploratory Factor Analysis (EFA) Findings}

EFA showed different factor structures: For example, according to Kaiser's eigenvalue test.: 10; Cartell's scree pilot test: 6; Velicer's MAP test: 5; and Horn's PA test: 4 factors were determined. The total variance explained with 6 factors is $\% 62$.

Table 3

Factor Loadings for 6-factor Solution in EFA

\begin{tabular}{|c|c|c|c|c|c|c|c|}
\hline & 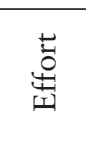 & 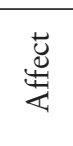 & $\frac{\mathscr{g}}{\stackrel{\pi}{\pi}}$ & ن & $\begin{array}{l}\vec{\Delta} \\
\stackrel{\Delta}{\Delta} \\
\stackrel{\Delta}{\Xi}\end{array}$ & 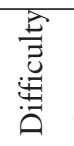 & 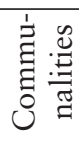 \\
\hline & 1 & 2 & 3 & 4 & 5 & 6 & \\
\hline 1. I tried to complete all of my statistics assignments & .859 & & & & & & .771 \\
\hline 2. I worked hard in my statistics course & .741 & & & & & & .676 \\
\hline 14. I tried to study hard for every statistics test & .766 & & & & & & .691 \\
\hline 27. I tried to attend every statistics class session & .768 & & & & & & .641 \\
\hline 3. I like statistics & & .404 & & & & & .512 \\
\hline 4. I feel insecure when I have to do statistics problems & & .527 & & & & & .723 \\
\hline 15. I get frustrated going over statistics tests in class & & .602 & & & & & .593 \\
\hline 18. I am under stress during statistics courses & & .693 & & & & & .705 \\
\hline 19. I enjoy taking statistics courses & & .735 & & & & & .686 \\
\hline 28. I am scared by statistics & & .444 & & & & & .757 \\
\hline
\end{tabular}

Sequel to Table 3 see on the next page. 
Sequel to Table 3.

\begin{tabular}{|c|c|c|c|c|}
\hline 1 & 2 & 3 & 4 & 6 \\
\hline 7. Statistics is worthless & & .440 & & .636 \\
\hline $\begin{array}{l}\text { 9. Statistics should be a required part of my professional } \\
\text { training }\end{array}$ & & .568 & & .475 \\
\hline 10. Statistical skills will make me more employable & & .405 & & .428 \\
\hline 13. Statistics is not useful to the typical professional & & .614 & & .508 \\
\hline $\begin{array}{l}\text { 16. Statistical thinking is not applicable in my life } \\
\text { outside my job }\end{array}$ & & .624 & & (459. \\
\hline 17. I use statistics in my everyday life & & .371 & & .462 \\
\hline $\begin{array}{l}\text { 21. Statistical conclusions are rarely presented in } \\
\text { everyday life }\end{array}$ & & .738 & & .563 \\
\hline $\begin{array}{l}\text { 25. I will have no application for statistics in my } \\
\text { profession }\end{array}$ & & .619 & & .627 \\
\hline 33. Statistics is irrelevant in my life & & .545 & & .582 \\
\hline $\begin{array}{l}\text { 5. I have trouble understanding statistics because of } \\
\text { how I think }\end{array}$ & & & .400 & .562 \\
\hline $\begin{array}{l}\text { 11. I have no idea of what's going on in this statistics } \\
\text { course }\end{array}$ & & & .559 & .471 \\
\hline 26. I make a lot of math errors in statistics & & & .633 & .558 \\
\hline 31. I can learn statistics & & & .586 & .739 \\
\hline 32. I understand statistics equations & & & .368 & .686 \\
\hline 35. I find it difficult to understand statistical concepts & & & .355 & .518 \\
\hline $\begin{array}{l}\text { 12. I am interested in being able to communicate } \\
\text { statistical information to others }\end{array}$ & & & .581 & .584 \\
\hline 20. I am interested in using statistics & & & .616 & .620 \\
\hline $\begin{array}{l}\text { 23. I am interested in understanding statistical } \\
\text { information }\end{array}$ & & & .794 & .798 \\
\hline 29. I am interested in learning statistics & & & .595 & .736 \\
\hline 6. Statistics formulas are easy to understand & & & & -.377 .421 \\
\hline 8. Statistics is a complicated subject & & & & -.454 .493 \\
\hline 22. Statistics is a subject quickly learned by most people & & & & -.418 .506 \\
\hline 24. Learning statistics requires a great deal of discipline & & & & -.422 .525 \\
\hline 30. Statistics involves massive computations & & & & -.470 .438 \\
\hline 34. Statistics is highly technical & & & & -.489 .525 \\
\hline $\begin{array}{l}\text { 36. Most people have to learn a new way } \\
\text { do statistics }\end{array}$ & & & & -.551 \\
\hline
\end{tabular}

Extraction Method: Principal Component Analysis. Rotation converged in 30 iterations.

When looked at the total variance explained, the communalities, and the factor loads, 6 factor solution was preferred for theoretical reasons. The original version and Turkish adaptation of the scale was reported to have a 6 -factor structure. In order to retain comparability, 6-factor solution was thought to be more appropriate in this study.

\subsubsection{Confirmatory Factor Analysis (CFA) Findings}

CFA confirmed 6 factor solution with sufficient overall goodness-of-fit parameters. In other words, sufficient $\chi 2 / \mathrm{sd}=3,79$, good RMSEA $=0.06$, good GFI $=0.96$, good $\mathrm{AGFI}=0,96$ and good CFI = 0,97 (Sümer, 2000). 


\subsubsection{Latent Trait Analysis (LTA) Findings}

\section{Dimensionality}

Latent trait analyses using Rasch model in Item Response Theory confirmed that each factor is unidimensional and independent with RMSEA values $\leq .05$ for all six factors.

\section{Item Quality}

Latent trait analyses using Rasch model in Item Response Theory revealed sufficient item parameters (discrimination ( $\mathrm{a} \geq 1.00$ for all items), difficulty (balanced distribution of popular and unpopular items) and information).

\section{Standard Scores}

Calculation of Rasch scores for each 6 factors proved and provided standard scores for persons.

\subsubsection{Reliability Analysis}

\section{Item-Total Correlations}

For all factors item-total correlations varied between .47 and .77 which indicate good internal reliability.

\section{Point Estimates}

Emmioğlu (2011) reported alpha between. 69 and .90. In this study Cronbach's alpha, Mc Donald's omega and GLB point estimates were found between .72 and .85. which indicate acceptable to good internal reliability (Peters, 2014).

\section{Confidence Intervals}

In this study Cronbach's alpha, Mc Donald's omega confidence intervals were found between $[.72, .74]$ to $[.84, .86]$ which indicate good internal reliability (Peters, 2014).

\subsubsection{Pretest Scores for t-tests for Independent Samples}

The findings of prestest scores for six factors of the scale for control and treatment groups are shown in Table 3.

Table 4

Pretest Scores

\begin{tabular}{lccccc}
\hline & $\begin{array}{c}\text { Rasch Mean Scores } \\
\text { for Control Group }\end{array}$ & $\begin{array}{c}\text { Rasch Mean Scores } \\
\text { for Experiment } \\
\text { Group }\end{array}$ & $\begin{array}{c}\text { I - J } \\
\text { Exp. - Cont. } \\
\text { Mean }\end{array}$ & t & $p$ \\
\hline Affect & 9.87 & 9.91 & 0.04 & -0.223 & .412 \\
\hline Cognitive Competence & 9.93 & 10 & 0.07 & -0.370 & .356 \\
\hline Value & 10.25 & 10.16 & -0.09 & -0.422 & .337 \\
\hline Difficulty & 9.96 & 10.02 & 0.06 & -0.267 & .395 \\
\hline Interest & 10.03 & 9.92 & -0.11 & -0.621 & .268 \\
\hline Effort & 10.14 & 10.06 & -0.08 & -0.495 & .311 \\
\hline
\end{tabular}


The pretest scores show that there are no significant difference between control and experiment groups in terms of the six factors of attitudes towards mathematics.

\subsubsection{Posttest Scores for t-tests for Independent Samples}

The findings of prestest scores for six factors of the scale for control and treatment groups are shown in Table 3.

Table 5

Posttest Scores

\begin{tabular}{lccccr}
\hline & $\begin{array}{c}\text { Rasch Mean Scores } \\
\text { for Control Group }\end{array}$ & $\begin{array}{c}\text { Rasch Mean Scores } \\
\text { for Experiment } \\
\text { Group }\end{array}$ & $\begin{array}{c}\text { I - J } \\
\text { Exp. - Cont. } \\
\text { Mean }\end{array}$ & t & $p$ \\
\hline Affect & 9.91 & 10.34 & 0.43 & -6.91 & .00 \\
\hline Cognitive Competence & 9.94 & 10.32 & 0.38 & -6.61 & .00 \\
\hline Value & 10.26 & 10.5 & 0.24 & -3.69 & .00 \\
\hline Difficulty & 9.98 & 10.25 & 0.27 & -3.85 & .00 \\
\hline Interest & 10.02 & 10.33 & 0.31 & -4.81 & .00 \\
\hline Effort & 10.12 & 10.3 & 0.18 & -2.28 & .00 \\
\hline
\end{tabular}

The pretest scores show that there are significant differences between control and experiment groups in terms of the six factors of attitudes towards statistics.

\subsubsection{General Mixed Model Intercept Findings}

The findings of prestest scores for six factors of the scale for control and treatment groups are shown in Table 3.

Table 6

General Mixed Model Intercept Findings

\begin{tabular}{lccc}
\hline & Mean square & $\mathrm{F}$ & $\mathrm{p}$ \\
\hline Affect & $19,395.497$ & $13,820.832$ & .000 \\
\hline Cognitive Competence & $19,413.307$ & $14,180.857$ & .000 \\
\hline Value & $19,281.235$ & $11,439.609$ & .000 \\
\hline Difficulty & $20,394.965$ & $23,939.044$ & .000 \\
\hline Interest & $19,442.705$ & $10,655.726$ & .000 \\
\hline Effort & $19,519.563$ & $13,962.002$ & .000
\end{tabular}

Table 5 shows that the common effect of treatment and cohort was found significantly positive in all 6 dimensions of attitudes towards statistics.

\section{Discussion}

There are two types of results in this study:

\subsection{Use of Excel}

Quoting from Mitlin, Hickey, and Bebbington (2006), that “...it is far more important to ask how the term "development" is used to serve particular (increasingly global) interests rather than to ask what it means", Ketonen (2016) uses the term "sustainable 
development" in the meaning of "sustainability". According to Ketonen (2016), the idea of sustainability is either a characteristic to legitimize actions or something hands on, a tangible result that is created through a creative process, not something theoretical, which can be calculated or measured. In this study, the term ESD was taken as Education for Sustainability which was used in the meaning of "Education for Generations". ICT integration to ESD was taken as finding and using ICT tools that can be accessed widely and used for generations. ICT integration to ESD was addressed in this study at teacher training level since it's considered as one of the most effective ways of sharing professional experiences and a medium of sustainable education in the society (Kabadayı, 2016).

Using Ms Excel in basic statistics (Gomes et al., 2006; Slezak et al., 2014), especially in teaching statistics (Carlberg., 2014) was previously shown as feasible. This study confirmed the same argument that using Excel in Teacher Education in Statistics Course is feasible in most topics. Excel seems to have some advantages over the other commercials. For example, since Microsoft Windows is a standard in most countries of the World, most pre-service teachers seem to possess Microsoft Office and Excel. Teaching a subject using a software which could be bought and possessed by everyone meets the social aspect of sustainable development which contains ideas of equality and social justice (Hopwood, Mellor and O'Brien, 2005). Excel has eye-catching tables and graphs which help construct new concepts easily. Researchers claim that good graphs should summarize data without distortion (Cleveland, 1994; Oliver, 1998). In this sense, Excel can be argued to provide good graphs. Most pre-service teachers have basic file-management skills in Excel which is a real time-saver in such an effort to instruct a whole course using a software. Natek and Zwiling (2014), mentioned the same advantage of Excel that it can be used in statistical analysis because it's normally available to most professors. Thus, when designing a course that will be fully instructed with a software, it should be considered that being widely available is an important criteria. Despite this advantages, Duller (2008) recommends teaching statistictics using Excel with a critical point of view for a few reasons i.e., he finds some Excel functions a little bit tricky, unmeaningful or inaccurate. On the other hand, he agrees with the proposition suggested in this study that Excel is and ICT for generations (sustainability) because it's a well known and frequently used software (Duller, 2008).

\subsection{Attitudes}

Attitudes towards statistics is important. The more the students have positive attitudes towards statistics the higher statistics outcomes they had, for example higher statistics grades at the end of taking statistics course or a willingness to use statistics in the future (Emmioglu, 2011). In this study, using Excel applications and homework assignments and class presentations in Teacher Education in Statistics Course improved attitudes towards statistics in the experiment group more than the control group. This improvement happened in all six factors of attitude as affect, cognitive competence, value, difficulty, interest and effort. This result contributes to the results of previous work which reported mostly intellectual (Carlberg, 2014; Nash and Quon, 1996; Price and Zhang, 2007) or practical (Hunt, 2003, 2005, 2007; Newfeld, 2016) gains. The "Statistics AttitudesOutcomes Model" proposed that effort had significant effect on statistics outcomes (Emmioglu, 2011), and the Eccles' Model proposed that spent effort was the predictor of students' achievement in statistics (Eccles and Wigfield, 2002). Tempelaar et al. (2007), 
found similar results that effort had direct significant effect on students' statistics achievement. Therefore, the reason why attitudes improved in this study might be the increased spent effort or effort beliefs in the treatment group where Excel applications and tasks were used. Garfield and Ben-Zvi (2007), reported that "Students who may not be strong in mathematics may work hard and enjoy statistics". This confirms the former sentence that in the treatment group pre-service teachers spent more effort and thus might have enjoyed statistics more. They claim that students learn and enjoy statistics by active involvement in learning activities. After reviewing current literature on teaching statistics, the authors also suggest using technological tools to teach statistics to help students visualize and explore data for making sense (Garfield and Ben-Zvi, 2007). The findings in this study about improved attitudes are also in line with the findings of Garfield \& Chance (2000), who stated that learning is enhanced if students have ample opportunities to express ideas and get analytical and timely feedback on their ideas. The pre-service teachers in the experiment group have ample opportunities to express ideas and get analytical and timely feedback on their ideas when working on Excel applications after the instruction, and during completing and presenting their tasks on the same statistics topics.

\subsection{Recommendations for Further Studies}

In this study it was shown that using Excel in Teacher Education in Statistics Course was effective and improved attitudes of pre-service elementary science teachers towards statistics. Similar experiments might be performed for other undergraduate courses in other departments. Emmioğlu (2011) recommends that the attitudes towards statistics be investigated in nation-wide and cross-cultural contexts. The researchers might also look for the answers of how, who and how long questions in the future. In other words, the mechanisms behind attitude improvement might be explored. For example, one possible mechanism behind attitude improvement might be individuals' performances and achievement choices (Eccles \& Wigfield, 2002). The researchers might want to look at in which groups of pre-service teachers attitude improvement happens. Moreover, it's important to examine how long the improvements in attitude last. Kabaday1 (2016), developed an innovative instructional In-service Training Model (INSET) model in Turkish context where he showed that the participant pre-service teachers want to be equipped with prerequisite skills to prepare projects in teaching and to manipulate the technological devices for sustainable education. It's important to reveal pre-service teachers' willingness to take part in any effort to foster sustainable education and this might provide insight into how long the improvements in attitudes last.

\section{References}

Bartz, S. (2007). Excelblatt vereinfacht Stochastik. Stochastik in der Schule, 27(2), 25-29. Borovcnik, M. (2007). Das Sammelbildproblem - Rosinen und Semmeln und Verwandtes: Eine rekursive Lösung mit Irrfahren. Stochastik in der Schule, 27(2), 19-24. Carlberg, C. (2014). Statistical Analysis: Microsoft Excel 2013. Que Publishing. Chiesi, F., \& Primi, C. (2010). Cognitive and non-cognitive factors related to students' statistics achievement. Statistics Education Research Journal, 9(1), 6-26. 
Cleveland, W. (1994). The elements of graphing data. Summit. New Jersey: Hobart Press.

Doane, D. (2004). Using simulation to teach distributions. Journal of Statistics Education, 12(1).

Duller, C. (2008). Teaching statistics with excel a big challenge for students and lecturers. Austrian Journal of Statistics, 37(2), 195-206.

Eccles, J. S., \& Wigfield, A. (2002). Motivational beliefs, values, and goals. Annual Review of Psychology, 53(1), 109-132.

Emmioğlu, E. (2011). The relationship between mathematics achievement, attitudes toward statistics, and statistics outcomes: A structural equation model analysis. Unpublished doctoral dissertation). Middle East Technical University, Ankara, Turkey.

Garfield, J., \& Ben-Zvi, D. (2007). How students learn statistics revisited: A current review of research on teaching and learning statistics. International Statistical Review, 75(3), 372-396.

Gomes, P. P., Passeri, L. A., \& de Albergaria Barbosa, J. R. (2006). A 5-year retrospective study of zygomatico-orbital complex and zygomatic arch fractures in Sao Paulo State, Brazil. Journal of oral and maxillofacial surgery, 64(1), 63-67.

Hopwood, B., Mellor, M., \& O’Brien, G. (2005) Sustainable development: mapping different approaches. Sustainable Development, 13(1), 38-52.

Horgan, G. W. (1999). Use of spreadsheets for demonstrating experimental power and variability. Journal of Statistics Education, 7(1).

Hunt, N. (2003). Handling Continuous Data in Excel. Teaching Statistics, 25(2), 42-45.

Hunt, N. (2005). Using Microsoft Office to Generate Individualized Tasks for Students. Teaching Statistics, 27(2), 45-48.

Hunt, N. (2007). Individualized Statistics Coursework Using Spreadsheets. Teaching Statistics, 29(2), 38-43.

Kabadayi, A. (2016). A Suggested In-service Training Model Based on Turkish Preschool Teachers' Conceptions for Sustainable Development. Journal of Teacher Education for Sustainability, 18(1), 5.

Ketonen, I. E. (2016). Sustainable Development, From Idea to Practice: A Case Study of an NGO in Cochabamba, Bolivia.

Kühleitner, M. (2007). Sammelbildproblem: Eine Simulation mit Excel. Stochastik in der Schule, 27(1), 24-26.

Makrakis, V. (2011). ICT-enabled education for sustainable development: Merging theory with praxis. In M. Youssef \& S. Aziz Anwar (Eds.), Proceedings of the 4th Annual Conference on e-Learning Excellence in the Middle East 2011 - in Search of New Paradigms for reEngineering Education (pp. 410-419). Dubai, UAE: Hamdan Bin Mohammed e-University.

Makrakis, V., \& Kostoulas-Makrakis, N. (2012). Course curricular design and development of the M. Sc. programme in the field of ICT in education for sustainable development. Journal of Teacher Education for Sustainability, 14(2), 5-40.

Microsoft. https://news.microsoft.com/bythenumbers/ms_numbers.pdf. Retrieved on 01.05.2016.

Mitlin, D., Hickey, S., \& Bebbington, A. (2006). Reclaiming development? NGOs and the challenge of alternatives. World Development, 35, 1699-1720. 
Nash, J., \& Quon, T. (1996). Issues in teaching statistical thinking with spreadsheets. Journal of Statistics Education, 4(1).

Natek, S., \& Zwilling, M. (2014). Student data mining solution-knowledge management system related to higher education institutions. Expert systems with applications, 41(14), 6400-6407.

Newfeld, D. (2016). A first assignment to create student buyin in an introductory business statistics course. Teaching Statistics.

Oliver, F. (1998). How to present information in graphs and diagrams. Notes on behalf of the Examinations Board of the Royal Statistical Society. Retrieved from http://www.therss.org.uk/exams/docs/diagrams.pdf, 2008-01-28.

Peters, G. J. Y. (2014). The alpha and the omega of scale reliability and validity: why and how to abandon Cronbach's alpha and the route towards more comprehensive assessment of scale quality. European Health Psychologist, 16(2), 56-69.

Price, B., \& Zhang, X. (2007). The Power of Doing: A Learning Exercise that Brings the Central Limit Theorem to Life. Decision Sciences Journal of Innovative Education, 5(2), 405-411.

Schau, C. (2003). Students' attitudes: The "Other" important outcome in statistics education. Paper presented at the Joint Statistical Meeting, Section on Statistics Education, San Francisco, CA.

Slezák, P., Bokes, P., Námer, P., \& Waczulíková, I. (2014). Microsoft Excel add-in for the statistical analysis of contingency tables. Int J Innovation Educ Res, 2(06), 90-100.

Sümer, N. (2000). Yapısal Eşitlik Modelleri. Türk Psikoloji Yazıları, 3(6), 49-74.

Tempelaar, D. T., Schim van der Loeff, S., \& Gijselaers, W. H. (2007). A structural equation model analyzing the relationship of students' attitudes toward statistics, prior reasoning abilities and course performance. Statistics Education Research Journal, 6(2), 78-102.

Correspondence concerning this paper should be addressed to Assist. Prof. Dr. Serhat Aydın, Karamanoğlu MehtmetBey University, Faculty of Education, Department of Elementary Education. Yunus Emre Campus, 70100 Karaman / Türkiye. Email: aydins@kmu.edu.tr 